\title{
ECO-COMICS AS AN EDUCATIONAL TOOL FOR TEACHING ENVIRONMENTAL JOURNALISM AND ESP
}

\author{
Polina Vasileva, Vadim Golubev \\ St. Petersburg State University, Russia \\ E-Mail: p.vasilyeva@spbu.ru;v.golubev@spbu.ru
}

\begin{abstract}
For the last forty years, environmental issues have gained importance across national borders. Journalists are expected to be national advocates for change in order to improve the quality of environmental health, conservation and social justice. Environmental studies emphasize a multi-disciplinary approach. The paper discusses the use of eco-comics in environmental journalism studies and promoting environmental awareness through journalism. The medium of comics has been around for many decades and comes in a variety of forms, from different cultural backgrounds; it is rich in material for academic study. Ecocomics for academic and professional purposes provide an inquiry-based content course designed to familiarize students with the fundamental concepts of the natural and social sciences, as well as humanities. English for Specific Purposes (ESP) focuses on combining theoretical and practice-based approaches. The theoretical part of the research contains a brief historical summary of comics and their uses in an educational setting. Special attention is devoted to eco-comics as influential medium of mass media to form public awareness. The authors highlight the role of eco-comics in encouraging students to be co-creators of interdisciplinary environmental journalism studies in English and environmental awareness campaigns. The paper contains practical results of an experimental case study of using ecocomics in the ESP classroom.
\end{abstract}

Key words: ESP, environmental education, multi-disciplinary approach, eco-comics

\section{INTRODUCTION}

Global sustainable future greatly depends on providing environmental education to create proper awareness so that the general public can come together to secure the planet's future. The new environmental movement has generated extended and intensive news coverage of ecological issues and awakened interest among journalism educators and prospective journalists in Russia and Europe. This results in new educational courses and programs. The media's primary environmental responsibility is to educate the public about the threats to the environment posed by global warming, industrialization, accumulation of toxic wastes, disposal of all wastes, and emission of poisonous gases. Media coverage should also inspire efforts in regards to energy conservation and alerting the public to the consequences of ignoring human impact on the environment.

Environmental education provided by higher education institutions has an important impact on training and preparing future generations for a green society. The purpose of the

Submitted September $9^{\text {th }}, 2019$, accepted for publication October $7^{\text {th }}, 2019$

(C) 2019 by University of Niš, Serbia | Creative Commons License: CC BY-NC-ND 
study is to examine the relationship between public awareness, attitude and environmental behavior of journalism students through eco-comics. This is important because they are expected to be future national advocates for improving the quality of environmental health, conservation and social justice. Our primary task is to identify future journalists' perception of climate change, the need to reduce greenhouse gas emissions and to use alternative energy, pollution, loss of biodiversity, more efficient use of natural resources, waste management, sustainable consumption, and impact of products on the environment (Boca Dana, 2019).

Some Russian researchers stress that there is no public environmental awareness in Russia despite the visible signs of this phenomenon (increasing average winter temperature in the Arctic zone of Russia by more than 3 degrees, reducing snow and ice coverage, flooding risk of coastal areas, etc.). The Russian mass media does not provide efficient and effective coverage of climate change issue (Vasilev, Vasileva, Tsvetkova, 2019). Environmental or climate change education is a key aspect for public awareness of the danger of climate change because it has provided a dialogue between communities, policy makers, stakeholders, researchers and citizens.

In 2015 the UN drafted the resolution on sustainable development adoption "Transforming our world: The agenda 2030 for Sustainable Development". The paper established 17 sustainable development goals including 169 associated targets which are drafted for stimulating initiative, monitoring performance and levering compliance. With regard to our research, it is worth emphasizing Goal 13 "Take urgent actions to combat climate change and its impacts". One of the targets to be achieved is the following: "Improve education, awareness-raising and human and institutional capacity on climate change mitigation, adaptation, impact reduction and early warning" (UN 2015, p.23).

Environmental education demands supporting learners to develop competencies that are transferable to new, uncertain and as yet unknown, or poorly defined situations. The media serves as an intermediary between scientists, policy makers, industry, and the public by translating scientific information for general consumption (Felpausch-Parker, 2015). According to the common scientific opinion, in most cases people get knowledge about science through mass media, not through scientific publications or direct involvement in science. Journalistic norms in reporting by the mass media also help to determine what is novel and relevant to its readership. The aim of environmental education is to teach and educate the public about the function of the environment and, particularly, how human beings can manage their behavior within a particular ecosystem.

There are many inquiry-based approaches for providing environmental education for university students. In our research we consider eco-comics as a powerful educational tool for fostering the effect of shaping public awareness of climate change. Environmental issues have become transnational; therefore, we have a new challenge to provide basic ecological knowledge in English via eco-comics. Thus, we consider English eco-comics as an educational tool crucial for promoting environmental literacy on a global scale.

\section{COMICS AS AN EDUCATIONAL TOOL}

Comics as an educational medium are focused on motivating students and developing critical thinking. The combination of pictures and texts can have a strong influence on improving learning. They are particularly popular with young children, since they are 
more appealing to them than traditional educational approaches. Comics can be regarded as a creative approach of narration and storytelling. As an educational tool, strip cartoon is a sequence of static images which present a story.

Due to the incredible popularity of superheroes comic books in the USA, many adults consider them children's literature. This is somewhat ignored by the academic community. In some countries such as Japan, however, comics are recognized as literature for adults. Some researchers (M.Tatalovic (2009), J.Oslo (2008), F.Lasarinis (2015), L.Gonick (1983)) identify science comics as a genre of comic books aimed to communicate science. Comics are widely used for teaching ESL and some authors (B.Zimmerman (2008), J.Lui (2004)) highlight its effectiveness for fostering reading, writing and creativity. Zimmerman (2008) points out that "comic strips provide the perfect vehicle for learning and practicing language" (B.Zimmerman, 2008 p.55).So it can be also regarded as a powerful educational tool for implementing in university curriculum.

Comics have rather long history but they obtained their popularity as a means of commenting on political and social issues in the middle of the 19th century. Such illustrations became known as cartoons. The 1930s saw comics to be used as an educational medium. Since that time the effectiveness of comics as medium for effective learning and development has been the subject of debate.

Rudolphe Topffer (1799-1846), known as the father of comic strips, emphasized that the picture-story, which critics disregard and scholars scarcely notice, has had great influence at all times, perhaps even more than written literature (McCloud, 1994). The American cartoonist Scott McCloud in his books Understanding Comics (1994) and Reinventing Comics (2000) discusses formal aspects of comics as a medium of communication. His books together with the other notable comic and graphic novel authors such as Art Spiegelman, Will Eisner, Alan Moore, Neil Gaiman and Garry Trudau can be considered as a prominent starting point for specifying comics medium as a separate form of communication, art and literature.

Summarizing the value of using comics in the classroom, we can distinguish the following:

1) motivational benefits and developing critical thinking;

2) a creative approach of narration and storytelling;

3) interdisciplinary links and multidisciplinary possibilities.

In a higher education setting, we should highlight two possible applications:

- teachers can use comics to develop and vary educational materials. In general teachers are not expected to have painting and artistic skills, comic strip artists could be a powerful medium to help them compose their educational scenarios in comics and combine them with text books and lecture materials;

- students can be encouraged to create their own comics. The process of creating comics is a means to develop creative thinking, personal expression, literacy development, and improve communication skills (Bitz, 2008).

In our experimental study we used both approaches. But we tried to give freedom to our students to create something new that could be really powerful and influential to form public environmental awareness via eco-comics. We provide the review of the students' eco-comics in the next section. 


\subsection{Comics in teaching science literacy}

Educational or science comics are relatively young in comparison with political or social ones. Promoting science literacy at the university level requires a multifaceted approach.

There are many opposite opinions how to teach science and what methods should be used to get the best results. Thus, Olson stresses that "media such as cartoons, web pages, graphs, charts and even "body language" are viable tools for reaching students. These alternative methods of delivering content are valuable to students, and students should be given an opportunity to work with these types of media" (Olson, 2008).

M. Talalovic identifies science comics as a special genre of comics designed to communicate science and educate the reader about some non-fictional, scientific concept or theme. He emphasizes that "educational science-themed comics may help to promote and explain science to students and the general public" (Tatalovic, 2009).

Larry Gonick's The Cartoon Guide series is one of the earliest adaptations of comics to science education with The Cartoon Guide to Genetics published in 1981. These series of comic books cover absolutely different subjects such as chemistry, physics, history etc. The Manga Guide is another example of science educational comics books including 41 volumes in Japanese with 12 English translated ones that guide students through Biochemistry, Linear Algebra, and Physiology at high school and college levels.

Environmental topic is also presented in comics. For instance, the Ozzy Ozone comics were produced by the United Nations Environment Programme. This interactive comic provides information and activities about the ozone layer, environment, climate change and the atmosphere (www.ozzyozone.org).

The Paris Climate Change Agreement (2015) stimulated a number of educational projects for building public awareness of climate change. Thus, the Portuguese researcher Bruno Pinto wrote the book, Special Report: Adaptation to Climate Change in Portugal, a publication developed as part of the award-winning project ClimAdaPT.Local. He says the book is a great resource to teach about climate change in classrooms, as well as a way to reach young people who otherwise might not see this global issue as something that affects them personally. He thinks that its format is particularly appreciated by teenagers and can be a good introduction and complement formal education on climate change as comics have good potential for science communication (Pinto, 2017).

In this regard one more environmental project should be mentioned titled Dreams of a low carbon future by James Mckay from the University of Leeds (the UK) (McKay, 2014). The aim of this project was to develop engineering researchers' communication skills, by enabling them to work with schoolchildren and professional artists to produce a 'graphic novel' (comic) that explores the children's visions of a sustainable 'low carbon' future society.

Unfortunately, most educational eco-comics are focused on schoolchildren or even pre-school children. Overall, students of journalism have a lack of special scientific environmental knowledge so creating eco-comics for environmental journalism studies could engage students and increase their desire to learn more complicated material related to climate change mitigation. As a medium that is motivating, visual, intermediary, permanent, and popular, comics are an immediate draw for educators teaching an introductory science course or a science communicator who wants to explain the importance of a specific subject, like global warming, to the general public. 
One of the main advantages of science comics is their format. They have flourished as web comics (Bird and Moon(2013), Beatrice the Biologist (2014)), which are free and easily shared on social media platforms. Science comics, whether they are printed books or downloaded web comics, can easily become part of a science communicator's toolkit. Taking into account all the above, we stress the primary purpose of our study is to create climate change awareness of students of journalism through eco-comics.

\section{RESULTS}

\subsection{Discussion of experimental study}

During the spring term (February 2019 -May 2019) we ran an experimental project at the School of Journalism and Mass Communications of St. Petersburg State University entitled Public environmental awareness through eco-comics. The experimental study involved 38 first-year students. The experimental project study consisted of four stages: 1) introductory stage; 2) analytical stage; 3 ) activity-oriented stage; 4) evaluating stage.

Initially, we studied the material from English textbooks and read texts related to environmental issues paying particular attention to thematic vocabulary. It is noteworthy that environmental vocabulary contains a great number of common and special terms which meanings are not always clear to students (e.g. carbon dioxide emissions, greenhouse gases, energy efficient, industrial waste, toxic fumes, pollution, fossil fuels, urban sprawl, deforestration, illegal dumping, and sustainable development). For boosting students' memory capacity a special mindmap (Fig.1) was proposed.

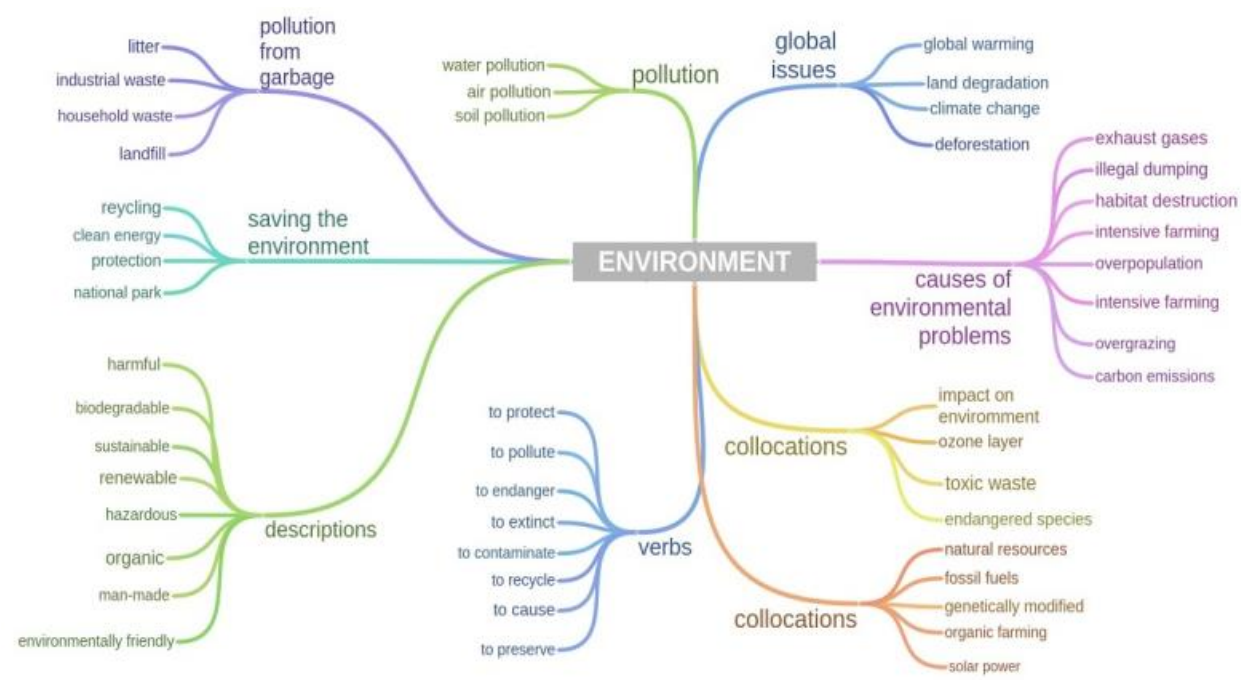

Fig.1 Environmental vocabulary mindmap

After that students watched a couple of YouTube videos explaining the reasons and consequences of climate change and discussed how they can contribute to climate change mitigation on daily basis. 
The analytical stage of the experiment was focused on discussion of eco-comics. The students were given some comics related to the current top environmental issues. The task was to identify the most impressive and funniest comics, as well as the easiest and most complicated ones to understand. This discussion generated different interpretations of the stories in relation to the environment.

At the third stage the students were asked to make or draw their own eco-comics. They could choose any environmental issue that concerned them most. Frankly speaking, many students were highly motivated and inspired to be involved in the inquiry-based learning process. As a result, they created amazing eco-comics in different genres. Some students used Web tools to create eco-comics (Fig.3) while the others drew them themselves (Fig.2).

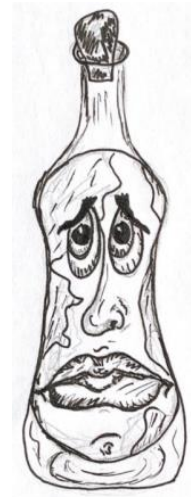

Fig. 2 Separate garbage collection

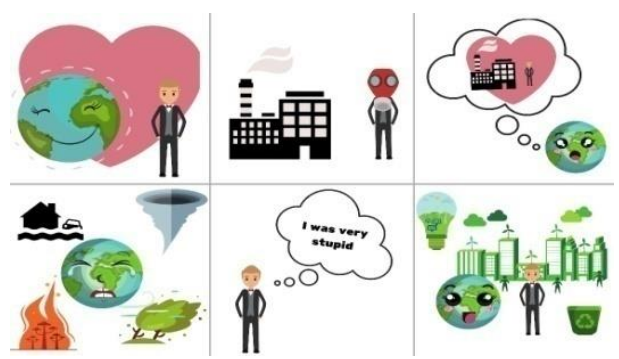

Fig. 3 Industrial pollution

Most students created comics on unconventional topics related to environmental issues. They tried to create eco-comics for the non-specialists who are interested in a relatively pain-free way to learn about the basic ecological concepts underlying our modern technological lifestyle. Topics such as air and water pollution, global warming, poor waste management, ozone depletion, dropping litter, reducing energy consumption and more are depicted in the students' eco-comics. Most students presented only single-frame cartoons which have some similarities with book illustrations. Others created comic strips on environmental issues that are more similar to comic books than cartoons as they also narrated a story through a short sequence of forms. They could legitimately be studied on their own account, and could either be included in or excluded from science comics studies. 


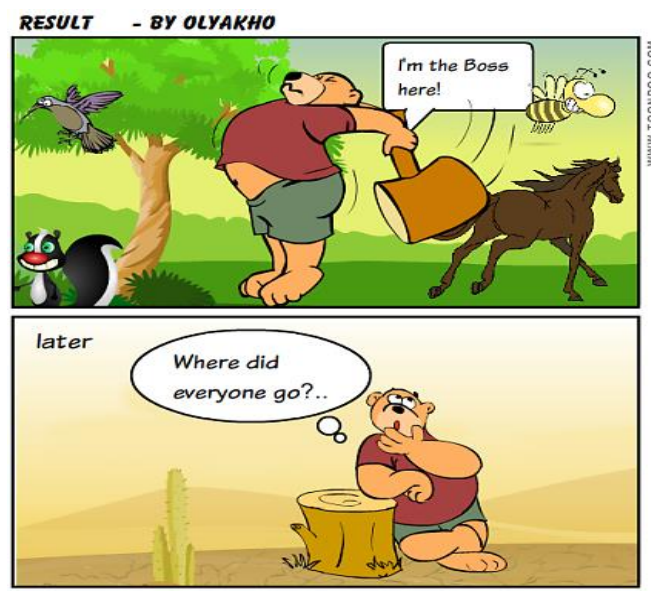

Fig. 4 Deforestation

A couple of students tried to create superhero or romance comic books. One of the best ecocomics was a superhero comic book concerning ozone layer destruction. Its plot is a traditional one showing the fight between the good and the evil. The superhero Ozone (marked as its chemical compound O3) is struggling against villain Freon and Superhero's mission is to save our planet (Fig.5). The other one was made in a romantic genre portraying love and a developing personal relationship between the main characters sparkled by their involvement in a public environmental campaign. It concerned waste sorting and providing public incentives for creating environmentally friendly places of living. While the storylines in both eco-comics may be rather primitive and predictable as they are examples of stereotypical storytelling narration with happy endings, but it is one of the ways of communicating serious scientific concepts to the

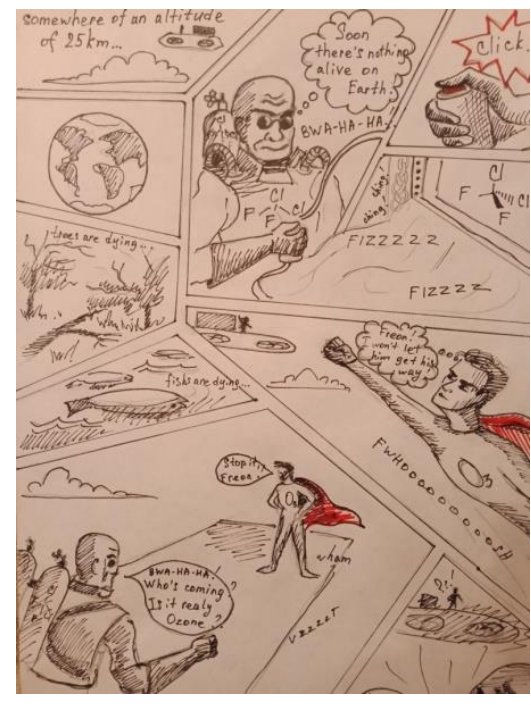

Fig. 5 Superhero eco-comics public on issues of tremendous implications. In this regard eco-comics prove our research hypothesis that they are an effective educational tool for developing environmental awareness in students of journalism.

Some comic strips presented their authors as main heroes using biographical storytelling, which was rather emotional and appealing. Moreover, they used their personal life experience to demonstrate how individuals could contribute to climate change mitigation doing simple things on a daily basis. One example advocated a refusal to use plastic packaging for fruit and vegetables as it is depicted in these eco-comic strips (Fig.6). 


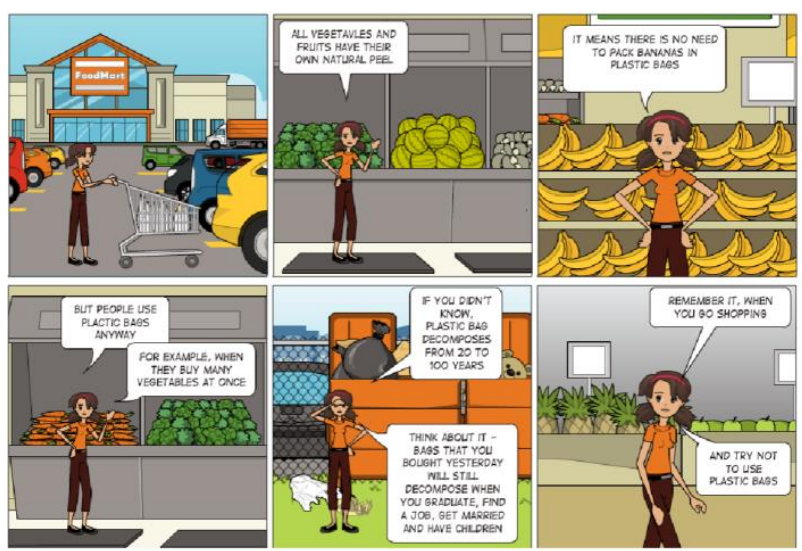

Fig. 6 Biographical eco-comics

Students often used symbolic-mythological images to highlight the importance of environmental issues. They depicted mermaids, wild animals or just unrealistic creatures (some kind of aliens). Overall, the allegorical interpretation of climate change is perfectly depicted in the single-frame cartoons presenting our planet as a melting ice-cream or being sick with a rising temperature. The most common and primitive eco-cartoon image of our planet is the illustration of the Earth in dark colors with tears and grimace (Fig. 7).
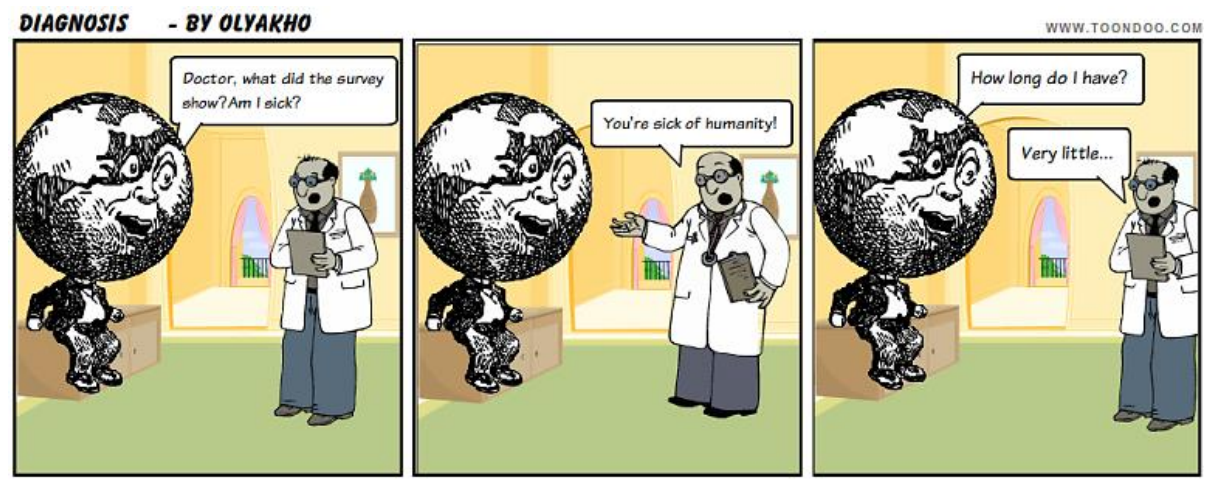

Fig. 7 Global warming

The main drawback of the students' eco-comics was rather poor English. However, our primary task was to awaken students' interest and awareness of climate change. Our further study will tackle the literacy aspect.

\subsection{Evaluation results}

The final, evaluating, stage of the experiment took place three weeks after presenting eco-comics projects. The students were offered to answer a questionnaire that consisted of seventeen factual questions about climate change (CC). The purpose of the survey was to identify the respondents' awareness of climate change and reveal contemporary public 
perception concerning global warming. Moreover, the respondents answered the questions about their information sources and trust in the information sources related to CC. Five questions were about their attitudes towards CC (evaluation of the level of the problem's gravity, their personal influence on CC drivers, and the impact of $\mathrm{CC}$ on their personal life). The questions focused on the concepts which were discussed during the experiment. For example, we asked the respondents to write what facts they knew about climate change, what caused climate change and how it was personally important to them, what activities they could do on a regular basis to mitigate climate change. The questionnaire also included a question regarding what they thought were the most effective educational tools in teaching English. We tried to design our questionnaire in order to find out people's perception of climate change and what educational approaches can be used to facilitate students' awareness of it.

We processed the questionnaire of 38 respondents to identify the journalism students' perception of the environmental sphere and to determine the environmental issues that concern them the most. As we can see from the bar chart (Fig. 8) the top three issues are air and water pollution, climate change and using up the earth's resources. If we compare the bar chart results with the figures in the pie chart (Fig. 9), we can see different priority of environmental issues. Almost half of the students depicted climate change as the main target of environmental protection. The remarkable fact that almost $23 \%$ of students devoted their eco-comics to litter and how it was possible to tackle the problem on a daily basis. In the questionnaire, only eleven percent marked this issue of the most concern. It can be explained by the fact that we focused on what everyone can do to make their place of living 'greener'.

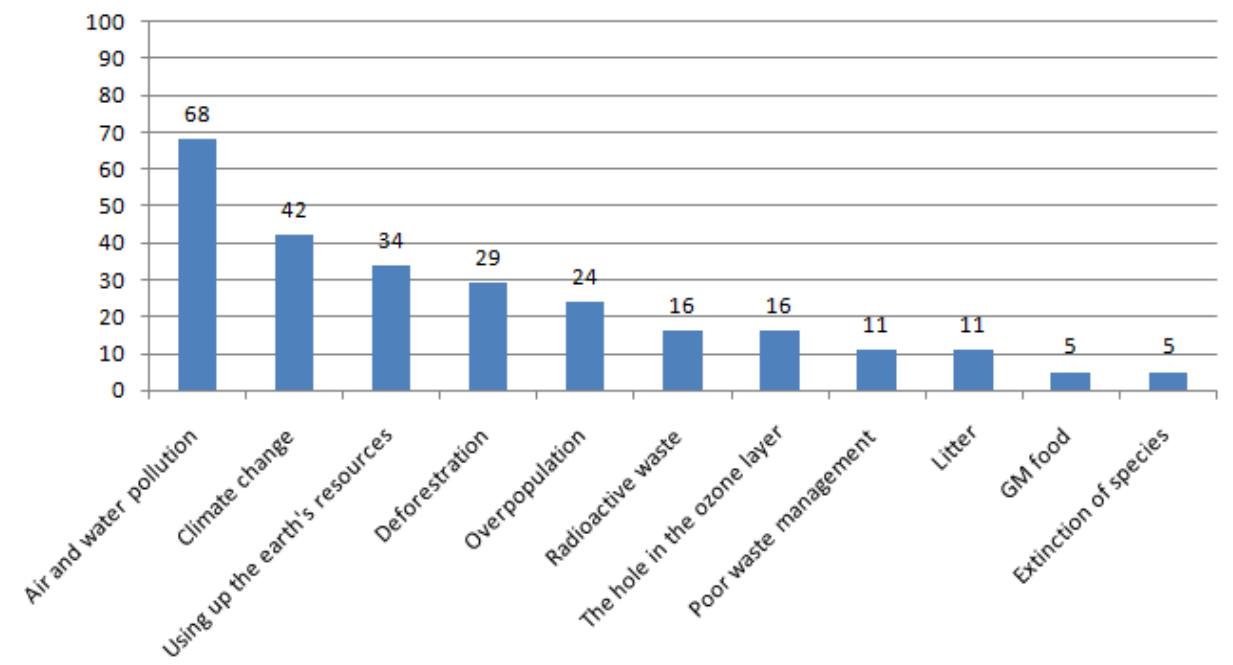

Fig. 8 Students' awareness of environmental issues (survey results) 


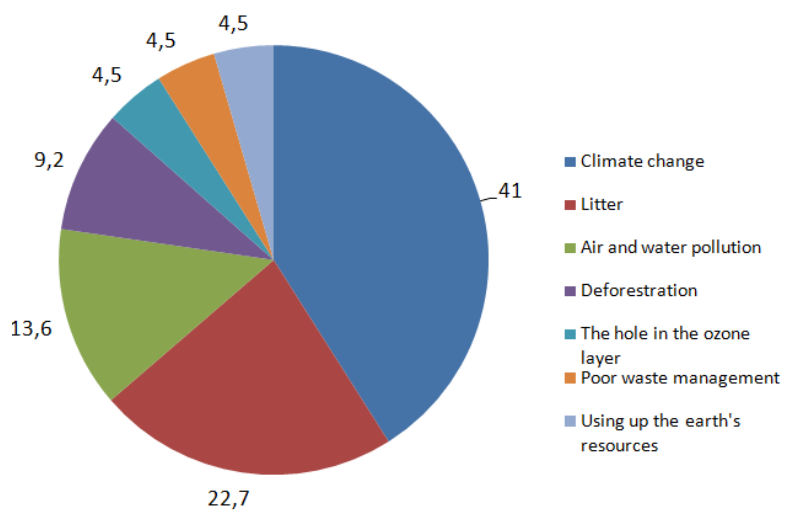

Fig. 9 Environmental issues presented by students in eco-comics

In terms of the sources of getting information about climate change, Internet, schools and higher education institutions occupy the first two leading positions (Fig. 10). So it proves the idea of expediency environmental studies in secondary and tertiary curriculum. Eco-comics as an educational tool can be effective on social media platforms.

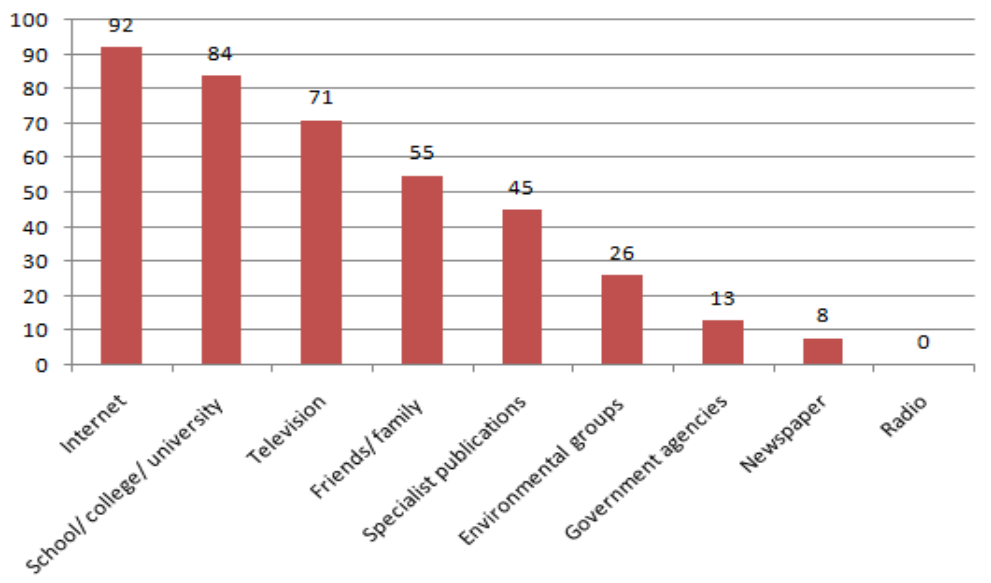

Fig. 10 Information sources of climate change (survey results)

Unfortunately, very few of the future journalists read newspapers or listen to the radio. They get their information from the Internet. The surprising fact the survey revealed was that the students of journalism did not trust information about climate change from the media. About $60 \%$ of respondents trust the media a little or not very much. A scientist's opinion is more competent and reliable source of information for them. The most devastating result is that almost $30 \%$ of the students do not find the issue of climate change personally important to them even after having learned of its serious implications for the planet (Fig. 11). 


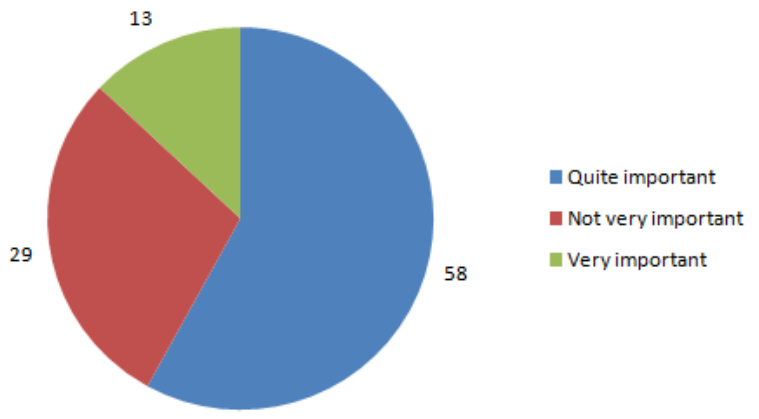

Fig. 11 Personal importance of climate change (survey result)

This picture provides a break for eco-comics not only as an effective approach for shaping environmental awareness in journalism students but an innovating technique of teaching English for Specific Purposes. More than half of the respondents put eco-comics into the same category of innovating teaching methods as game-based digital educational platforms and participatory learning. This makes us optimistic about using eco-comics in the ESP classroom.

\section{CONCLUSIONS}

Environmental issues such as climate change are a global threat to human civilization; thus, it is vitally important to promote environmental awareness at all levels of education. The media's primary task is to educate the public about various matters including the environment. To shape public opinion, future journalists must be linguistically and environmentally literate in order to be able to translate scientific concepts into the general language.

The purpose of the study was to how using eco-comics we could increase environmental awareness of Russian journalism students and boost their English competence. Through speaking activities, writing and drawing comics journalism students acquired English environmental lexis and developed their visual scientific literacy. Visual scientific literacy can be defined as the ability to construct meaning from images. It is a form of critical thinking that enhances student's intellectual capacity. Our experimental study proved that eco-comics could be considered to be effective vehicle to communicate scientific ideas and construct persuasive environmental discourse.

\section{REFERENCES}

Bitz, M. (2008). "A rare bridge: The Comic Book Project Connects Learning with Life". Teachers\& Writers, 39, p. 2 - 13.

Boca, G. D. \& Saraçlı S. (2019). "Environmental Education and Student's Perception for sustainability". Sustainability 11(1553), p. 1-18.

Eisner, W. (1996). Graphic Storytelling and Visual Narrative. Tamarac, Florida, Poorhouse Press. 
Feldpausch-Parker, A. M., Burnham, M., Melnik, M., Callaghan, M. L. \& Selfa, T. (2015). News Media Analysis of Carbon Capture and Storage and Biomass: Perceptions and Possibilities. Energies 8(4), p. 3058-3074.

Lazarinis, F., Mazaraki A., Verykios V. S. \&Panagiotakopoulos C. (July, 2015). Ecomics in teaching: evaluating and using comic strip creator tools for educational purposes. Paper presented at The 10th International Conference on Computer Science \& Education. Fitzwilliam College, Cambridge University, UK, p.305-309.

Liu, J. (2004). Effects of Comic Strips on L2 Learners' Reading Comprehension.TESOL Quarterly, Issue 38, p. 225 - 243.

McCloud, S. (1994).Understanding Comics: the Invisible Art, New York, Harper Collins.

McKay, J. (2014). Dreams of a low carbon future.https://womenwriteaboutcomics.com/ 2014/02/climate-change-comics-dreams-of-a-low-carbon-future/Accessed 11 July 2019.

Olson, J. (2008). The comic strip as a medium for promoting science literacy, Northridge, CA: California State University.

Pinto, B. (2017). Special Report: Adaptation to Climate Change in Portugal. https://unfccc.int/ news/art4climate-comic-art. Accessed 11 July 2019.

Tatalovic, M. (2009). Science comics as tools for science education and communication: a brief, exploratory study. Journal of Science Communication, 8(04), p. 1-17.

Vasilev Y., Vasileva P., Tsvetkova A. International review of public perception of CCStechnologies. 19th International multidisciplinary scientific geoconference SGEM 2019. Ecology, economics, education and legislation. Volume 19, Issue 5.1. 30 June 6 July, 2019. - Albena, Bulgaria. p. 415-422.

Zimmerman, B. (2008). Creating comics fosters reading, writing, and creativity. The Educational Digest, 74 (4), p. 55-57.

UN (2015) Transforming our world: the 2030 Agenda for Sustainable Development. Resolution adopted by the General Assembly on 25 September 2015. http://www.un.org/ es/comun/docs/index.asp?symbol=A/RES/70/1\&referer=/spanish/\&Lang=E. Accessed 11 July 2019. 